\title{
Differentiation of Five Commercially Available Triphala churnas of an Ayurvedic Formulation by Elemental Fingerprint
}

\author{
Venkata Siva Satyanarayana Kantamreddi ${ }^{12^{*}}$, Thirumala Veni Vasupalli ${ }^{1}$, Murali Krishna Malasani ${ }^{2}$ and Simhachalam Boddana ${ }^{3}$
}

Venkata Siva Satyanarayana Kantamreddi ${ }^{1,2^{*}}$, Thirumala Veni Vasupalli', Murali Krishna Malasani ${ }^{2}$ and Simhachalam Boddana $^{3}$

${ }^{1}$ Centre for Chemical Analysis, Central Research Laboratory (CRL), GIT, GITAM University, Visakhapatnam, INDIA ${ }^{2}$ S.V. Enviro Labs \& Consultants, INDIA, Auto Nagar, Visakhapatnam, INDIA ${ }^{3}$ Department of Mathematics, GIT, GITAM University, Visakhapatnam, INDIA

\section{Correspondence}

Venkata Siva Satyanarayana Kantamreddi,

Assistant Professor of Chemistry, Centre for Chemical Analysis, Central Research Laboratory, GIT, GITAM University, Visakhapatnam, Andhra Pradesh, INDIA.

Phone: +91-9866787845, +91-9703945669

E-mail: kantamreddi@gmail.com, vssnk@ yahoo.com, vssnk@gitam.edu

\section{History}

- Submission Date: 04-07-2016;

- Review completed: 22-08-2016;

- Accepted Date: 10-09-2016.

\section{DOI : 10.5530/pj.2017.1.20}

Article Available online

http://www.phcogj.com/v9/i1

\section{Copyright}

(C) 2016 Phcog.Net. This is an openaccess article distributed under the terms of the Creative Commons Attribution 4.0 International license.

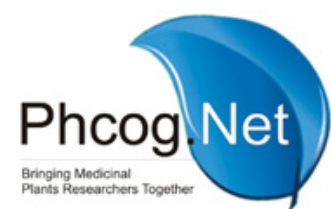

\begin{abstract}
Introduction: Triphala churna (TPC) is one of the well known Ayurvedic powdered preparations of Indian System of Medicine and is used in the treatment of various diseases. Elemental pattern of TPC was developed in order to investigate the identity and quality of commercial TPC drugs. Method: Inductively coupled plasma mass spectrometry (ICP-MS) was used for the quantitative determination of ten essential and trace elements in five marketed samples of Triphala churna. The concentration patterns of these elements were deciphered by multivariate statistical analysis such as hierarchical cluster analysis (HCA), fuzzy c-means (FCM) and k-means (KM) cluster analysis. Results: The elemental concentrations ranged from $1.3 \mathrm{mg} / \mathrm{kg}$ (Cr, TPC3) to $14220 \mathrm{mg} / \mathrm{kg}$ (K, TPC4). The elemental fingerprint of Triphala churna was established based on three churnas viz. TPC1, TPC3 and TPC5, which were found in one cluster with a very high degree of similarity by KM, FCM and HCA techniques. Conclusion: Based on the results, the graphical pattern of elements detected in these samples can be considered as elemental fingerprint of Triphala churna and can be used for authentication and/or to determine the quality of commercial TPC drugs.

Key words: Triphala churna, Ayurvedic Drugs, Elemental Fingerprint, Inductively Coupled Plasma Mass Spectrometry, k-Means, Fuzzy c-Means, Hierarchical Cluster Analysis
\end{abstract}

\section{INTRODUCTION}

According to the estimations of World Health Organization (WHO), around $80 \%$ of the world population still primarily rely on herbal drugs. ${ }^{1}$ Herbal drugs are gaining popularity worldwide, and there are many branded and unbranded formulations are available for therapeutic and cosmetic uses. ${ }^{2,3}$ But, the cases of adverse health consequences caused by the use of herbal medicines have also been increasing simultaneously. ${ }^{4,5}$ One of the reasons for this is the large number of adulterated and spurious drugs released into the market. Hence, the pharmacognostical screening consists of macroscopic and microscopic fingerprinting of herbal drugs is given preference in scientific studies. But, in recent years, a new method called "Elemental Fingerprint Analysis" was proposed to solve this problem..$^{6-10}$

Several inorganic minerals are usually taken by plants for nutrition but about twenty five elements are identified as essential for optimal growth, development and reproduction of plants, called "bioessential." The bioaccumulation of non-essential elements (As, $\mathrm{Cd}, \mathrm{Hg}, \mathrm{Pb}$, etc.) by plants are probably due to contaminated soil and other environment factors. Many factors influence nutrient uptake for plants such as climate, atmospheric depositions, the concentrations of metals in soil, the nature of soil on which the herbs are grown and the degree of maturity of plant at the time of harvest. ${ }^{11-12}$ However, each plant species maintain a certain balance of absorption of various elements due to their genetic nature. So, the uptake and bioaccumulation of elements, especially essential elements by plants are distinctive.
Consequently, the elemental pattern of each drug is characteristic with respect to the ingredients in it and it can be easily found that each herbal medicine is corresponds with a unique fingerprint pattern. So, the identity and quality of herbal medicines can easily be evaluated with the help of fingerprint. Based on this concept, various studies have been carried out on inorganic element patterns of medicinal drugs, medicinal plants, food and crops, etc., for provenance or region of origin of the samples. ${ }^{6,7}$ Infact, a few studies have been reported on Ayurvedic drugs based on inorganic elemental fingerprints. ${ }^{10}$ In view of this, the concentration of elements present in Triphala churna of different manufacturers were analyzed using inductively coupled plasma combined with mass spectrometry (ICP-MS) and pattern in element concentrations were deciphered by hierarchical cluster analysis (HCA), fuzzy c means (FCM) and k means (KM) cluster analysis.

Triphala is a herbal blend which is popularly used in the Ayurvedic system as a general health tonic and also for treating a variety of disease conditions. It is generally used to improve overall body health as it improves digestion and metabolism. It is a mixture of equal proportions of three dried fruits, Terminalia chebula Gaertn Retz. (haritaki, Combretaceae), Terminalia bellirica Roxb. (bibhitaki, Combretaceae) and Embellica officinalis Gaertn. (amalaki, Euphorbiaceae). Triphala is mainly used in case of weak digestion and constipation and it is also used when excess acid is released in stomach. It is used as a blood purifier to increase red blood cell count as well as hemoglobin count. It is also prescribed in conditions like diabetes, 
hepatitis, alzheimer's disease, glaucoma, conjunctivitis and some inflammatory conditions. ${ }^{13-14}$

\section{MATERIALS AND METHODS}

\section{Sample collection}

The analyzed Triphala churna drugs were procured from registered Ayurvedic shops at Visakhapatnam, India. The batch number, date of manufacture (DoM) and date of expiry (DoE) are recorded and kept available in the Central Research Laboratory, GIT, GITAM University, Visakhapatnam, India. The brand names were blinded and coded in sequential order (i.e. TPC1, TPC2, TPC3, TPC4 and TPC5).

\section{Experimental and Instrumental Details}

The analyses were performed on PerkinElmer NexION 300 ICP-MS system using low flow concentric Nebulizer \& Cyclonic spray chamber. The analysis was carried out by Kinetic Energy Discrimination mode (KED mode) using Helium (He) as collision gas to remove poly-atomic interferences. Detailed instrumental parameters are tabulated in Table 1.

\section{Sample Preparation}

The dried herbal samples were accurately weighed $(0.25 \mathrm{gm})$ and digested using $\mathrm{HNO}_{3}$ and $\mathrm{H}_{2} \mathrm{O}_{2}$ in a microwave digestion system. The final volume was made up to $25 \mathrm{ml}$ using ASTM type I water (Milli Q Water).

\section{Chemicals and Standards}

Working standard concentrations of $1,5,10,25,50,100 \mu \mathrm{g} / \mathrm{l}$ were prepared by a serial dilution of PerkinElmer Pure Plus multi-element standard with concentration of $10 \mathrm{mg} / \mathrm{l}$ whereas higher standard concentrations were prepared at mg/kg level for metals, $\mathrm{Na}, \mathrm{K}, \mathrm{Mg}$, Ca and Fe. A calibration blank was prepared in 2\% nitric acid (Supra-pure, E- Merck) medium with ASTM type I water.

\section{Statistical Analysis}

The analysis has been carried out by the pattern recognition methods such as hierarchical cluster analysis (HCA), $k$-means (KM) and fuzzy $c$-means (FCM). These methods are implemented in MatlabR2010a for windows. The data is presented by a data matrix $Z$ in which rows constitute the samples and the columns constitute the elements of the samples.

Hierarchical Cluster Analysis (HCA). Most hierarchical techniques fall into a category called agglomerative clustering. It is an unsupervised classification procedure that involves a measurement of the similarity between objects to be clustered, which seeks to build a hierarchy of clusters. ${ }^{15-16}$ The results of hierarchical clustering are usually presented in a dendrogram.

KM Analysis. The $k$-Means algorithm is widely used due to its efficiency. It is an iterative algorithm which optimizes of its objective function and results the classification of data or objects. ${ }^{17-18}$

The objective function is given as

$$
J(V)=\sum_{i=1}^{c} \sum_{k=1}^{N}\left\|z_{k}-v_{i}\right\|^{2}
$$

Where $\left\|z_{k}-v_{i}\right\|^{2}$ is the Euclidean distance calculated between $k^{\text {th }}$ object, $Z_{k}$ and $i^{\text {th }}$ centroid, $v_{i}$.

FCM Analysis. The fuzzy $c$-means (FCM) algorithm is one of the most widely used methods in fuzzy clustering. ${ }^{18-20}$ It is also an iterative algorithm which optimizes of its objective function and results the classification of data or objects. In this method a membership value ranged from 0 to 1 is assigned to each object by using a membership function. This feature enables that every object belongs to every cluster with various membership grades or values. $U=\left[\mu_{i k}\right]_{c \times N}$ represents the membership matrix of $Z$.
The objective function is given as

$\underbrace{\min }_{U, y}\left\{J(Z ; U, V)=\sum_{i=1}^{c} \sum_{k=1}^{N}\left(\mu_{i k}\right)^{m}\left\|z_{k}-v_{i}\right\|_{A}^{2}\right\}$ where $U \in M f_{c}$

here

$M_{f c}=\left\{U \in \mathfrak{R}^{c \times N} / \mu_{i k} \in[0,1], \forall i, k ; \sum_{i=1}^{c} \mu_{i k}=1, \forall k ; 0<\sum_{k=1}^{N} \mu_{i k}, \forall_{i}\right\}$

$m \in[1, \infty)$ is a weighting parameter that determines the degree of fuzziness, $V=\left[v_{1}, v_{2}, \cdots, v_{c}\right]$ where $v_{i} \in \mathfrak{R}^{n}$ is a vector of (unknown) cluster prototypes (centers). The prototypes, the membership function and the distance metrics are calculated by the equations given below i.e. (4), (5) and (6) respectively.

$$
\begin{aligned}
& v_{i}=\frac{\sum_{k=1}^{N}\left(\mu_{i k}\right)^{m} z_{k}}{\sum_{k=1}^{N}\left(\mu_{i k}\right)^{m}} \\
& \mu_{i k}=\left(\sum_{j=1}^{c}\left(\frac{D_{i k A}}{D_{j k A}}\right)^{\frac{2}{m-1}}\right)^{-1} \\
& D_{i k A}^{2}=\left\|z_{k}-v_{i}\right\|_{A}^{2}=\left(z_{k}-v_{i}\right)^{T} A\left(z_{k}-v_{i}\right)
\end{aligned}
$$

where $1 \leq i \leq c, 1 \leq k \leq N$,

\section{RESULTS AND DISCUSSION}

At present, there are many methods in the determination of inorganic elements, one of which is ICP-MS used for the quantitative determination of ten essential elements including four macronutrients $(\mathrm{Na}, \mathrm{K}, \mathrm{Ca}$ and $\mathrm{Mg}$ ) and six micronutrients ( $\mathrm{Fe}, \mathrm{Zn}, \mathrm{Cu}, \mathrm{Mn}, \mathrm{Cr}$ and $\mathrm{Ba}$ ) present in five different branded TPC drugs. Data are expressed on a dry weight basis. The levels of these elements are summarized in Table 2 and their concentrations in five Churnas are in the range of $\mathrm{Na}(456-762 \mathrm{mg} / \mathrm{kg})$, Mg (948 - 998 mg/kg), K (11057 - 14220 mg/kg), Ca (1888 - 2729 mg/

Table 1: Instrumental parameters of ICP-MS

\begin{tabular}{cc}
\hline ICP-MS System & Parameter \\
\hline RF power & 1600 Watts \\
Plasma gas flow & $17 \mathrm{l} / \mathrm{min}$ \\
Auxiliary gas flow & $1.2 \mathrm{l} / \mathrm{min}$ \\
Nebulizer gas flow & $1.0 \mathrm{l} / \mathrm{min}$ \\
Nebulizer & Glass concentric \\
Spray chamber & Cyclonic \\
Sample/Skimmer cones & Nickel \\
Scanning mode & Peak hoping \\
Detector mode & Dual mode \\
Calibration & Linear through zero \\
Number of sweeps & 20 \\
Dwell time & $50 \mathrm{~ms}$ \\
Number of readings & 1 \\
Number of replicates & 3 \\
KED gas flow (He) & $3.0 \mathrm{ml} / \mathrm{min}$ \\
\hline
\end{tabular}


Table 2: Concentration of elements in various marketed Triphala churna drugs

\begin{tabular}{ccccccc}
\hline \multirow{2}{*}{ Element } & \multicolumn{5}{c}{ Concentration $(\mathbf{m g} / \mathbf{k g})$} \\
\cline { 2 - 7 } & TPC1 & TPC2 & TPC3 & TPC4 & TPC5 & Range \\
\hline $\mathbf{N a}$ & 762 & 490 & 456 & 541 & 529 & $456-762$ \\
$\mathbf{M g}$ & 998 & 960 & 987 & 988 & 948 & $948-998$ \\
$\mathbf{K}$ & 12930 & 11057 & 13230 & 14220 & 12480 & $11057-14220$ \\
$\mathbf{C a}$ & 2536 & 2672 & 2721 & 1888 & 2729 & $1888-2729$ \\
$\mathbf{C r}$ & 2.7 & 5.1 & 1.3 & 3.8 & 2.1 & $1.3-5.1$ \\
$\mathbf{M n}$ & 45.2 & 22.8 & 32.9 & 29.2 & 27.6 & $22.8-45.2$ \\
$\mathbf{F e}$ & 1026 & 357 & 668 & 711 & 730 & $357-1026$ \\
$\mathbf{C u}$ & 7.5 & 6.0 & 4.3 & 5.2 & 4.2 & $4.2-7.5$ \\
$\mathbf{Z n}$ & 16.1 & 16.2 & 19.6 & 16.5 & 17.1 & $16.1-19.6$ \\
$\mathbf{B a}$ & 16.8 & 14.8 & 15.2 & 16.1 & 14.2 & $14.2-16.8$ \\
\hline
\end{tabular}
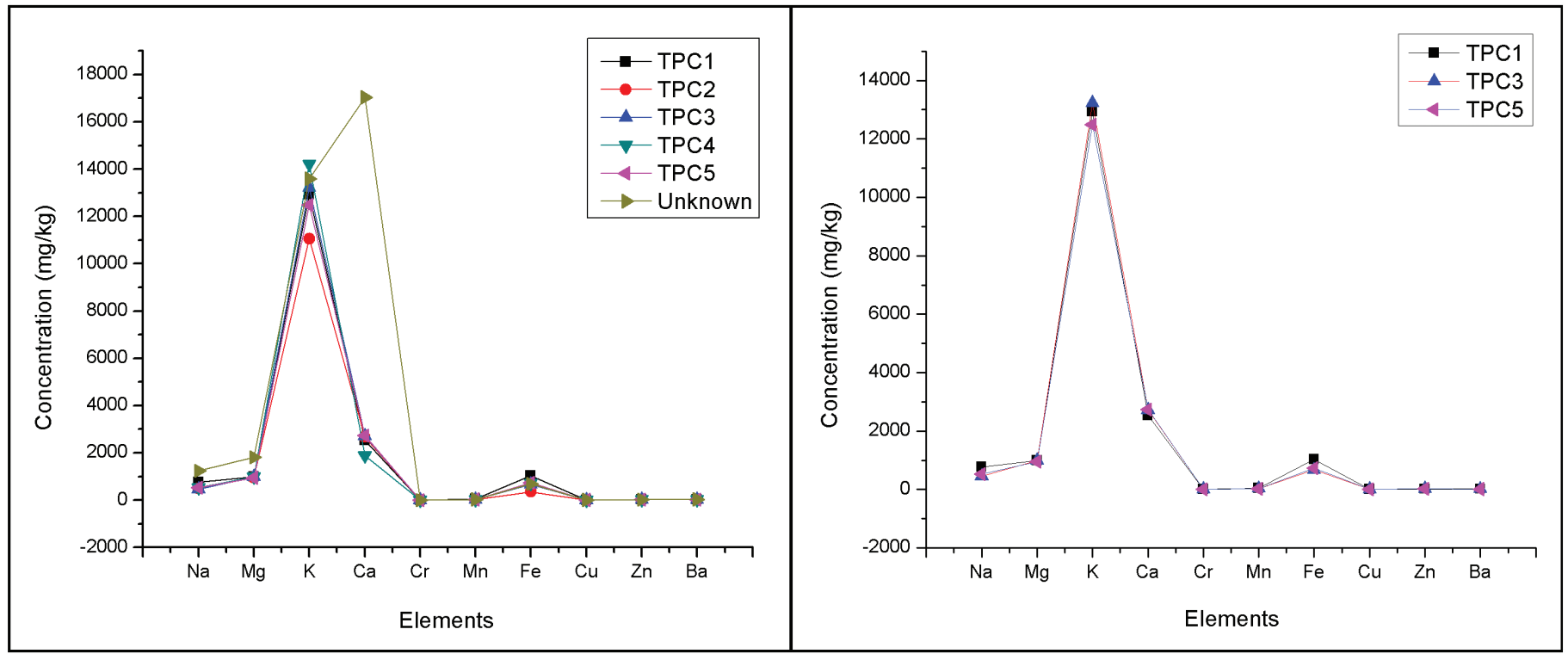

Figure 1: Elemental fingerprint of Triphala churnas drugs

$\mathrm{kg}), \mathrm{Cr}(1.3$ - $5.1 \mathrm{mg} / \mathrm{kg}), \mathrm{Mn}(22.8$ - $45.2 \mathrm{mg} / \mathrm{kg}), \mathrm{Fe}(357$ - $1026 \mathrm{mg} / \mathrm{kg})$, $\mathrm{Cu}(4.2-7.5 \mathrm{mg} / \mathrm{kg}), \mathrm{Zn}(16.1-19.6 \mathrm{mg} / \mathrm{kg})$ and $\mathrm{Ba}(14.2-16.8 \mathrm{mg} / \mathrm{kg})$. As expected, it was found that macronutrients are detected in all TPC samples at $\mathrm{g} / \mathrm{kg}$ levels as they are commonly present in all plants in good quantities called ubiquitous, while micro-essential elements are detected at $\mathrm{mg} / \mathrm{kg}$ levels. Among these elements, the bio-accumulation of $\mathrm{K}$ has the maximum concentration as found in TPC4 of all samples analyzed, which is $14220 \mathrm{mg} / \mathrm{kg}$ and the second highest accumulated element is Ca with concentration of $2729 \mathrm{mg} / \mathrm{kg}$ (TPC 5) whereas $\mathrm{Cr}$ was noticed to be the least accumulated element of $1.3 \mathrm{mg} / \mathrm{kg}$ (TPC3).

The graphical representation of content distribution of 10 elements among five Triphala churna brand samples were tested in this study is shown in Figure 1. The established element fingerprint is made by plotting metal (increasing order of atomic number) against the respective metal concentration on the $\mathrm{x}$ and $\mathrm{y}$ axes, respectively. Although a similar elemental pattern was noticed in all Triphala churna brands, the curves of TPC1, TPC3 and TPC5 samples are in good agreement and overlapped (Figure 1b), but, a slight deviation was observed in case of TPC2 and TPC4 samples (Figure 1a). An unknown churna sample was also tested and used to compare peak shape of Triphala churna. Interestingly, its elemental pattern was significantly differed with TPC samples (Figure 1a). This may be due to Triphala churna and unknown drug samples tested in this study are different kind of formulations. So, it is an indication that the elemental fingerprints are directly correlated to the ingredients used in drug formulation.

The observed minimal difference among TPC samples in Figure 1a of present study cannot be explained by using classical second order statistics (mean and covariance). In such cases, cluster analysis is recognized as an important technique to measure the degree of similarity between two individuals i.e. classifying data, finding clusters of a dataset based on similarities in the same cluster and dissimilarities between different clusters (groups). Many algorithms for clustering are available, wherein, hierarchical (HCA), fuzzy $c$-Means (FCM) and non-fuzzy $k$-Means (KM) algorithms are most popular and widely used. ${ }^{16-20}$ Therefore, these clustering techniques were applied for pattern reorganization computations of Triphala churna drugs.

\section{HCA Analysis}

HCA of samples was performed using the selected chemical descriptors as variables, squared Euclidian distance metric as a similarity measurement. Samples from different clusters are shown in Figure 2a and it shows 
Table 3: Acquired results of KM and FCM cluster analysis of different Triphala churnas

\begin{tabular}{ccccccc}
\hline \multirow{2}{*}{ Samples } & \multicolumn{3}{c}{ KM } & \multicolumn{3}{c}{ FCM } \\
\cline { 2 - 7 } & Cluster 1 & Cluster 2 & Cluster 3 & Cluster 1 & Cluster 2 & Cluster 3 \\
\hline TPC1 & 314.1691 & $1.4941 \mathrm{e}+03$ & $2.0125 \mathrm{e}+03$ & 0.9400 & 0.0388 & 0.0212 \\
TPC2 & $1.8804 \mathrm{e}+03$ & $3.2784 \mathrm{e}+03$ & 0 & $3.3470 \mathrm{e}-05$ & $1.1158 \mathrm{e}-05$ & 1.0000 \\
TPC3 & 402.0439 & $1.2973 \mathrm{e}+03$ & $2.1961 \mathrm{e}+03$ & 0.8803 & 0.0890 & 0.0306 \\
TPC4 & $1.5511 \mathrm{e}+03$ & 0 & $3.2784 \mathrm{e}+03$ & $1.0306 \mathrm{e}-04$ & 0.9999 & $2.3125 \mathrm{e}-05$ \\
TPC5 & 417.5629 & $1.9331 \mathrm{e}+03$ & $1.4728 \mathrm{e}+03$ & 0.8832 & 0.0429 & 0.0739 \\
\hline
\end{tabular}

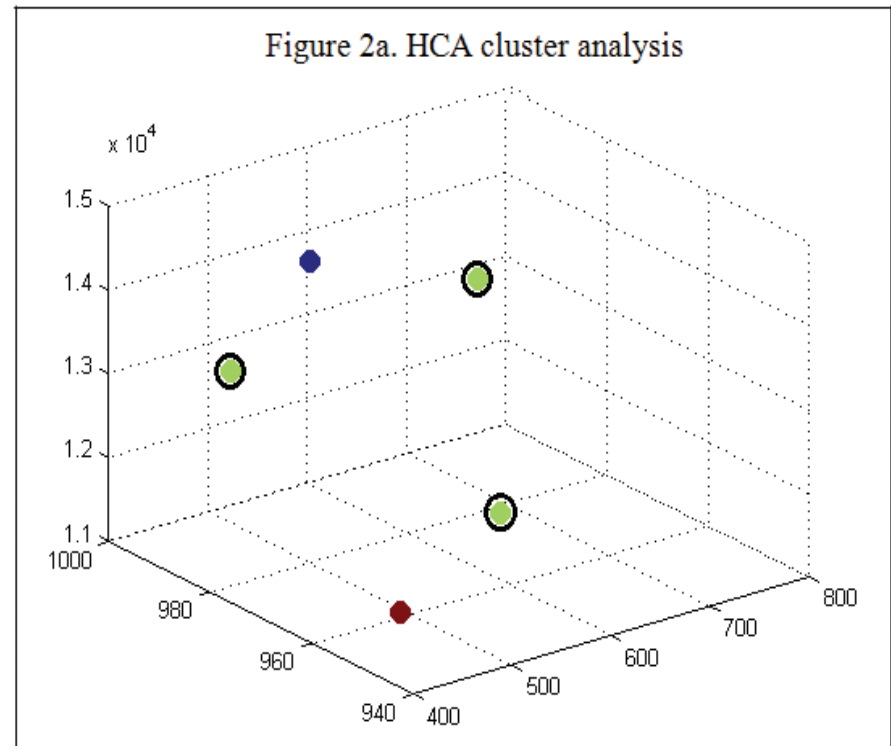

Figure 2b. HCA dendrogram

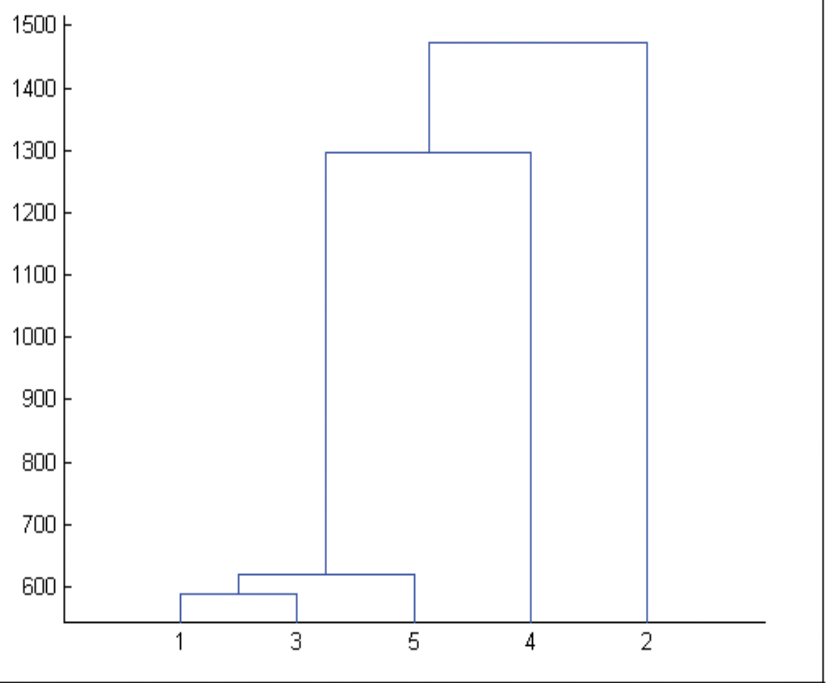

Figure 2: HCA cluster analysis and dendrogram of five TPC samples

a clear discrimination between samples. Based on Figure 2a, Triphala churnas are categorized into 3 groups i.e. TPC1, TPC3 and TPC5 were composed as a single cluster while other two samples (TPC2 and TPC4) were found as different clusters and away from main cluster.

The dendrogram (a binary tree) on the right in Figure 2 is the final result of the cluster analysis, with 4 nodes (Figure $2 \mathrm{~b}$ ). Interpretation of the structure of data is made much easier based on dendrogram as there are three samples (TPC1, TPC3 and TPC5) that are fairly close with high degree of similarity, while other two samples (TPC2 and TPC4) shows more than $50 \%$ dissimilarity and also, they separate with a large jump in the clustering levels. As a result three clusters of samples are yielded i.e. (TPC1, TPC 3, TPC 5), (TPC 4) and (TPC2), which can be labeled types 1, 2 and 3 respectively. In other words, the samples are categorized as given below.

\begin{tabular}{ccccc}
\hline TPC1 & TPC2 & TPC3 & TPC4 & TPC5 \\
\hline 1 & 3 & 1 & 2 & 1 \\
\hline
\end{tabular}

KM and FCM Analysis

The obtained results of KM and FCM analysis are summarized in Table 3. Interestingly, the results were obtained in both methods are same. The samples were categorized into three clusters by these methods, which are similar to HCA analysis and numbered as cluster1, cluster2 and cluster3. The first cluster comprises of TPC1, TPC 3 and TPC5, followed by a second cluster of TPC 4 and TCP 2 as a third cluster. The samples in cluster1 were found to have a high degree of similarity, giving the values of 314.1691 (TPC1), 402.0439 (TPC3) and 417.5629 (TPC5) in KM method, while 0.9400 (TPC1), 0.8803 (TPC3) and 0.8832 (TPC1) values in FCM method. The sample TCP4 was assigned to the cluster2 in both KM and FCM methods by giving the values of 0 and 0.9999 , respectively, while TCP 2 was found in cluster 3 by giving the values of 0 and 1.0000 , respectively (Table 3).

Thus, it can be concluded that there are three TPC drugs (TPC1, TPC3 and TPC5) having a high degree of similarity based on HCA, KM and FCM clustering techniques. Further, it corresponds with the proposed graphical representation (elemental pattern) in Figure $1 \mathrm{~b}$ and can be considered as the elemental fingerprint of Triphala churna, which helps to evaluate its identity and quality.

\section{CONCLUSION}

In brief, HCA, KM and FCM clustering techniques are effectively used to distinguish the TPC samples. Similar results were noticed in all three methods and found to have a high degree of similarity in between samples of TPC1, TPC3 and TPC5, which suggest that their elemental pattern i.e. the graphical representation that was proposed in this study is the final elemental fingerprint of Triphala churna (Figure 1b). In addition, the proposed statistical analysis (HCA / FCM / KM) is a simple and useful tool for the development of proper elemental fingerprints of herbal medicines. Therefore, this method can be extended to the other herbal medicines, which may have wide potential applications in their identification and quality control.

\section{CONFLICT OF INTEREST}

The authors have declared that there is no conflict of interests. 


\section{ACKNOWLEDGEMENTS}

The authors express their gratitude to the Head, Department of Chemistry and the Vice Chancellor of GITAM University, Visakhapatnam, for encouragement and facilitating necessary congenial environment to carry out research work. The authors are also thankful to Dr. U.V. Mallavadhani (Sr. Senior Principal Scientist \& Head, Natural Products Chemistry Division, IICT) and Dr. K. Tejaswani (Assistant Professor of English, GITAM University) for their assistance.

\section{ABBREVIATIONS USED}

TPC: Triphala churna; ISM: Indian System of Medicine; ICP-MS: Inductively coupled plasma mass spectrometry; HCA: Hierarchical cluster analysis; KM: $k$-Means; FCM: Fuzzy $c$-means; mg/kg: milligram/ kilogram; $\mu$ g/kg: microgram/kilogram; KED: Kinetic energy discrimination; GMP: Good manufacturing practice; WHO: World Health Organization; ASTM: American Society for Testing and Materials.

\section{REFERENCES}

1. Kantamreddi VSS, Wright CW. Screening Indian plant species for antiplasmodia properties - Ethnopharmacological compared with random selection. Phytother Res. 2012;26;(12):1793-9. http://dx.doi.org/10.1002/ptr.4651; PMid:22407797

2. Woods PW. Herbal healing. Essence. 1999;30(3):42-4.

3. Khan IA, Allgood J, Walker LA, Abourashed EA, Schelenk D, Benson WH. Determination of heavy metals and pesticides in ginseng products. J AOAC Int. 2001;84(3):936-9. PMid:11417656

4. Chan K. Some aspects of toxic contaminants in herbal medicines. Chemosphere. 2003;52(9):1361-71. http://dx.doi.org/10.1016/S0045-6535(03)00471-5

5. Stewart MJ, Moar JJ, Steenkamp P, Kokot M. Finding in fatal cases of poisoning attributed to traditional remedies in South Africa. Forensic Sci Int. 1999; 101 (3):177-83. http://dx.doi.org/10.1016/S0379-0738(99)00025-0

6. Szentmihalyi K, Csiktusnadi-Kiss GA, Keszler A. Method development for measurement of elements in Hungarian red wines by inductively coupled plasma optical emission spectrometry (ICP-OES). Acta Aliment. 2000;29(2):105-21.
http://dx.doi.org/10.1556/AAlim.29.2000.2.2

7. Kang HN, Yang MF, Chen B. Trace element determination in teas and discrimination analysis for teas. Rock and Mineral Anal. 2006;25(1):22-6.

8. Chen QL, Yao C, Ouyang PK. Determination of constant and trace elements in Ranunculus TernatusThunb by ICP-OES. Spectrosc Spect Anal. 2005;25(4):560-4.

9. Chen YX, Yu MG, Xu J. Differentiation of eight tea (Camellia sinensis) cultivars in China by elemental fingerprint of their leaves. J Sci Food Agr. 2009;89:2350-5. http://dx.doi.org/10.1002/jsfa.3716

10. Zheng Y, Zheng K, Liu E, LiY. Elemental fingerprint of herbal medicines formed by inductively coupled plasma atomic emission spectroscopy (ICP-AES). J Eng Sci Technol Rev. 2013;6(1):111-4.

11. Jin CW, Du ST, Zhang K, Lin XY. Factors determining copper concentration in tea leaves produced at Yuyao County, China. Food Chem Toxicol. 2008;46(6):2054-61. http://dx.doi.org/10.1016/j.fct.2008.01.046 ; PMid:18331777.

12. Yemane M, Chandravanshi BS, Wondimu T. Levels of essential and non-essential metals in leaves of the tea plant (Camellia sinensis L.) and soil of Wushwush farms, Ethiopia. Food Chem. 2008;107(3):1236-43.

13. Naik $\mathrm{GH}$, Priyasarsini $\mathrm{KI}$, Mohan $\mathrm{H}$. Free radical scavenging reactions and phytochemical analysis of Triphala, an Ayurvedic formulation. Curr Sci. 2006;90(8):1100-5

14. Gowda DV, G Muguli, PR Rangesh, Deshpande RD. Phytochemical and phar macological actions of Triphala: Ayurvedic formulation - a review. Int J Pharm Sci Rev. 2012;15(2):61-5.

15. Revelle W. Hierarchical cluster analysis and the internal structure of the tests. Multivar Behav Res. 1979;14:57-74. http://dx.doi.org/10.1207/ s15327906mbr1401_4; PMid:26766619

16. Chen Y, Yu M, Xu J, Chen X and Shi J. Differentiation of eight tea (Camellia sinensis) cultivars in China by elemental fingerprint of their leaves. J Sci Food Agric. 2009;89(14):2350-5. http://dx.doi.org/10.1002/jsfa.3716

17. Morissette L, Chartier S. The k-means clustering technique: General consider ations and implementation in Mathematica. Tutorials in Quantitative Methods for Psychol. 2013;9(1):15-24. http://dx.doi.org/10.20982/tamp.09.1.p015

18. Ghosh S, Dubey SK. Comparative analysis of k-means and fuzzy c-means algorithms. Int J Advanced Computer Sci App. 2013:4(4):35-9. http://dx.doi. org/10.14569/ijacsa.2013.040406

19. Suganya R, Shanthi R. Fuzzy c- means algorithm- a review. Int J Sci Res Pub. 2012;2(11):1-3

20. Das S. Pattern recognition using the fuzzy c-means technique. Int J Energy, Inf Com. 2013;4(1):1-14

\section{PICTORIAL ABSTRACT}

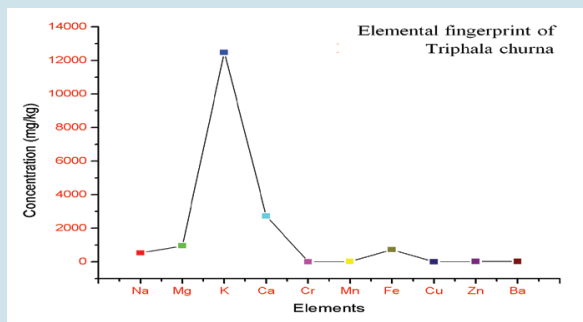

\section{SUMMARY}

- Triphala churna is a commercially important polyherbal preparation and being used in Ayurveda since ancient time.

- Five marketed samples of TPC were subjected to ICP-MS analysis for the determination of ten essential and trace elements.

- The increasing order of elemental concentrations is $\mathrm{Cr}<\mathrm{Cu}<\mathrm{Ba}<\mathrm{Zn}<\mathrm{Mn}$ $<\mathrm{Fe}<\mathrm{Na}<\mathrm{Mg}<\mathrm{Ca}<\mathrm{K}$.

- The elemental fingerprint of TPC was established based on HCA, KM and FCM clustering techniques.

- The proposed statistical analysis is a useful tool to extend to other herbal drugs for the development of proper elemental fingerprints.

\section{ABOUT AUTHORS}

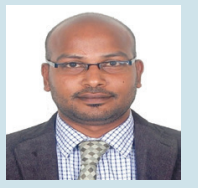

Venkata S. S. Kantamreddi, Chemist, received his PhD in Chemistry from University of Bradford, United Kingdom under Common wealth Scholarship. He has sixteen years of professional experience including teaching, research and industry. Expertise in isolation and structural elucidation of natural products, quantifications of bio-active markers, standardization of herbal drugs and in-vitro antiplasmodial screenings. His area of research interest is to develop potent antimalarials. He is currently working as an Assistant Professor of Chemistry at GITAM University, Visakhapatnam, India.

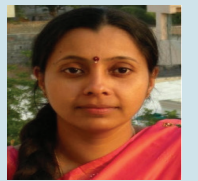

V. Thirumala Veni, having 15 years of professional experience in teaching, research and industry and obtained her M.Sc. in Bio-inorganic chemistry (1995) and M.Phil. in Chemistry (1997) from Andhra University, Visakhapatnam, India. At present, she is pursuing Ph.D. at GITAM University, Visakhapatnam. Her doctoral research is focused on the quality control of herbal drugs.

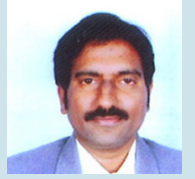

M. Murali Krishna is the Managing Partner of M/s S.V. Enviro Labs \& Consultants, Visakhapatnam, Andhra Pradesh, India. He is a Civil Engineer and obtained his M.Tech in Environmental Management from Jawaharlal Nehru Technological University (JNTU-Hyderabad, 2003). He is part of several professional bodies such as Institution of Engineers (India) and Victoria Sustainable Development (Victoria). His area of research interest is environmental studies. 


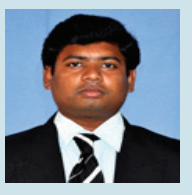

B. Simhachalam, obtained his M.Sc. (Applied Mathematics, 2005), M.Tech. (IT, 2009) and M.Phil. (Applied Mathematics,2007) from Andhra University, Visakhapatnam, India. He is presently working as an Assistant Professor in the Department of Mathematics at GITAM University, Visakhapatnam. He is specialized in applied group theory in Mathematics and his area of research interest is soft-computing.

Cite this Article: Kantamreddi VSS, Veni VT, Malasani MK, Simhachalam B. Differentiation of Five Commercially Available Triphala churnas of an Ayurvedic Formulation by Elemental Fingerprint.Pharmacogn J.2017;9(1):117-22. 